\title{
miR-128 is upregulated in epilepsy and promotes apoptosis through the SIRT1 cascade
}

\author{
DE-ZHE CHEN ${ }^{1}$, WEI-WEI WANG ${ }^{1}$, YAN-LING CHEN $^{1}$, XIA-FENG YANG $^{1}$, MIN ZHAO $^{1}$ and YAN-YAN YANG $^{2}$ \\ ${ }^{1}$ Department of Neurology, Liaocheng People's Hospital, Liaocheng, Shandong 252000; \\ ${ }^{2}$ Department of Neurology, Taishan Medical University, Taian, Shandong 271016, P.R. China
}

Received November 26, 2017; Accepted March 20, 2019

DOI: $10.3892 /$ ijmm.2019.4223

\begin{abstract}
The present study aimed to examine the functional and molecular effects of miR-128 in epilepsy, in order to investigate its potential protective mechanisms. Firstly, miR-128 expression in rats with lithium chloride-induced epilepsy was demonstrated to be increased compared with the control rats. Subsequently, results from an in vitro epilepsy model demonstrated that overexpression of miR-128 promoted nerve cell apoptosis, increased the protein expression of tumor protein $\mathrm{p} 53$, BCL2 associated X (Bax) and Cytochrome $c$, and enhanced caspase-3/9 activity, whereas it suppressed the protein expression of sirtuin 1 (SIRT1). In addition, these alterations may be reversed by the downregulation of miR-128. Furthermore, treatment with CAY10602, a SIRT1 agonist, reduced the effects of miR-128 on nerve cells in vitro. Treatment with pifithrin- $\beta$ hydrobromide, a p53 inhibitor, was additionally able to mitigate the effects of miR-128 in vitro. In conclusion, the present findings indicated that anti-miR-128 may exert neuroprotective effects in epilepsy, through the SIRT1/p53/Bax/Cytochrome $c /$ caspase signaling pathway.
\end{abstract}

\section{Introduction}

Epilepsy is a common disease. According to the World Health Organization, the average prevalence rate of epilepsy globally is $4-10 \%$, with a rate as high as $6-10 \%$ in developing countries $(1,2)$. At present, the world has witnessed $\sim 50$ million patients with epilepsy, $90 \%$ of these in developing countries (3). In China, there are $\sim 9$ million patients with epilepsy; additionally, there are $\sim 400,000-700,000$ novel cases. Typically, $30 \%$ of patients with epilepsy have developed into refractory epilepsy as a result of lack of effective prevention and treatment measures (4). Various antiepileptic drug therapies are available at present;

Correspondence to: Dr Wei-Wei Wang, Department of Neurology, Liaocheng People's Hospital, 45 Huashan Road, Liaocheng, Shandong 252000, P.R. China

E-mail: weiweiwang252000@163.com

Key words: miR-128, epilepsy, apoptosis, sirtuin 1, tumor protein p53, BCL2 associated X, Cytochrome $c$ however, satisfactory curative effect can hardly be achieved. Apart from genetic and environmental factors, the dysregulation of gene expression may result in expression alterations in genes associated with the pathogenesis of tolerant epilepsy (5). Such alterations stimulate mossy fiber sprouting, synaptic reorganization, neuron necrosis and regeneration, which may contribute to the abnormal excitatory loop and ultimately result in repeated attack of refractory epilepsy (6).

A recent study have demonstrated that microRNA (miRNA) may affect the protein translation at the post-transcriptional level (7). miRNA is a class of noncoding and endogenous single-stranded small molecule RNA 22nt in length (8). Primary miRNA (pri-miRNA) is first produced under the function of RNA polymerase from genome DNA (9), which is subsequently digested into the precursor miRNA with hairpin-like structure by RNA enzyme III family in the cell nucleus. The precursor is later transferred to the cytoplasm by exportin-5 and cut into double-strand miRNA by Dicer combined enzyme agent. The double-strand miRNA is unlocked by a helicase, which subsequently forms the mature single-stranded miRNA. The mature miRNA may subsequently selectively bind with RNA-induced silencing complex (RISC) to form the RISC complex. This complex then exhibits base complementarity pairing association with the 3' terminal untranslated region (UTR) of the target mRNA. Therefore, it may directly hydrolyze or restrain the target gene mRNA to regulate its expression (10). Computer prediction analyses and experimental studies to date have proved that a single miRNA is able to regulate multiple target mRNAs (9). Additionally, one-half of mRNAs in mammalian cells are regulated by one or more miRNAs. For these reasons, miRNA-associated transcription regulation has attracted wide scientific attention in the field of life sciences (8).

Acetylation and deacetylation are important processes in gene expression regulation and post-transcriptional protein modification (11). Silent mating-type information regulation 2 (Sir2) is the first discovered NAD-dependent histone deacetylase. It may prolong the replicative life span of saccharomycetes (12). Silent information regulator 1 (sirtuin 1 or SIRT1) is the mammalian histone deacetylase homologous to Sir2 (12). It is highly conserved in developmental stages and extensively expressed in all organs. SIRT1 can catalyze histones and a variety of non-histone proteins. Thereby, it may regulate gene expression and protein activity. It is a key enzyme during all physiological processes and is involved in 
a variety of biological effects. These biological effects include chromatin remodeling, transcription suppression, inflammatory response, energy metabolism, cell survival and apoptosis. A previous study has demonstrated that miR-183, miR-135a, miR-125b, miR-30c and miR-128 were upregulated at the seizure-associated phases and in patients with temporal lobe epilepsy (13). The present study aimed to evaluate the association between anti-miR-128 expression and antiepileptic treatment.

\section{Materials and methods}

Seizure induction. Adult male Sprague-Dawley rats (6-7 weeks; 180-230g) were obtained from the Laboratory Animal Center of Taishan Medical University (Tai'an, China) and kept in a controlled standard environment $\left(22 \pm 2^{\circ} \mathrm{C} ; 50-60 \%\right.$ humidity) with food and water available ad libitum and a 12-h light/dark cycle. The rats were randomly divided into two groups: Control group $(n=6)$, and epilepsy model group $(n=8)$. All rats were anesthetized using $35 \mathrm{mg} / \mathrm{kg}$ pentobarbital sodium. Epilepsy model rats were injected subcutaneously with kainic acid $(5 \mathrm{mg} / \mathrm{kg})$, and $10 \mathrm{~min}$ later they received a second injection of kainic acid $(2.5 \mathrm{mg} / \mathrm{kg})(14)$. The control group rats were subcutaneously injected with normal saline. After the induction of epilepsy at 3 days, rats were sacrificed using decollation under $35 \mathrm{mg} / \mathrm{kg}$ pentobarbital sodium. The present study was approved by the Institutional Animal Care and Ethics Committee of Liaocheng People's Hospital (Liaocheng, China).

Cell culture and transfections. Rat pheochromacytoma (PC12) cells were obtained from The Type Culture Collection of the Chinese Academy of Sciences (Shanghai, China) and cultured in Dulbecco's modified Eagle's medium (Gibco; Thermo Fisher Scientific, Inc., Waltham, MA, USA) containing 10\% fetal bovine serum (Gibco; Thermo Fisher Scientific, Inc.), in $5 \% \mathrm{CO}_{2}$ and $95 \%$ air. Anti-miR-128 mimics (5'-AGAGACCGG UUCACGGUGAUU-3'), miR-128 mimics (5'-UCACAGUGA ACCGGUCUCUUU-3') and negative control mimics (5'-UUC UCCGAACGUGUCACGUTT-3') were acquired from Sangon Biotech Co., Ltd. (Shanghai, China). PC12 cells (1x10 ${ }^{6}$ cells) were transfected with $100 \mathrm{ng}$ miR-128 mimics, $100 \mathrm{ng}$ anti-miR-128 mimics or $100 \mathrm{ng}$ negative control mimics using Lipofectamine ${ }^{\circledR} 2000$ reagent (Thermo Fisher Scientific, Inc.). After $4 \mathrm{~h}$ of transfection, the medium was changed and the cells were used for subsequent experimentation.

Cell proliferation assay and lactate dehydrogenase ( $L D H)$ activity levels. MTT reagent was added into cells and cultivated for $4 \mathrm{~h}$ at $37^{\circ} \mathrm{C}$. Dimethyl sulfoxide was subsequently added and cultivated for another $20 \mathrm{~min}$ at $37^{\circ} \mathrm{C}$. Absorbance was measured at $492 \mathrm{~nm}$. LDH activity levels were measured using an LDH activity kit (cat. no. C0016; Beyotime Institute of Biotechnology, Haimen, China) and absorbance was measured at $450 \mathrm{~nm}$.

Apoptosis rate. Cell was washed with PBS and centrifuged at $2,000 \mathrm{x} \mathrm{g}$ for $10 \mathrm{~min}$ at $4^{\circ} \mathrm{C}$. Cells were fixed with $4 \%$ paraformaldehyde for $15 \mathrm{~min}$ and stained with Annexin V-fluorescein isothiocyanate (FITC)/propidium iodide (cat. no. 556570;
BD Biosciences, San Jose, CA, USA) for 10 min in the dark at room temperature. The cell apoptosis rate was measured using a flow cytometer (BD Biosciences) and analyzed using FlowJo 7.6.1 (FlowJo, LLC, Ashland, OR, USA).

Caspase-3 activity assay. Hippocampi and cells were obtained and washed with PBS, lysed with radioimmunoprecipitation buffer (Beyotime Institute of Biotechnology) and protein concentrations were determined using a bicinchoninic acid protein (BCA) protein assay kit (Beyotime Institute of Biotechnology). A total of $5 \mu \mathrm{g}$ protein from each sample was incubated with Caspase 3 and 9 activity kit (cat. nos. C1116 and C1158; Beyotime Institute of Biotechnology) reagents for $2 \mathrm{~h}$ at $37^{\circ} \mathrm{C}$, according to the manufacturer's protocol. Absorbance was measured at $405 \mathrm{~nm}$.

Reverse transcription-quantitative polymerase chain reaction analysis. Total RNA was isolated from brain tissues using RNAiso Plus (Takara Biotechnology Co., Ltd., Dalian, China), according to the manufacturer's protocol. Total RNA $(1 \mu \mathrm{g})$ was synthesized into cDNA using PrimeScript RT Reagent kit with gDNA eraser (Takara Biotechnology Co., Ltd.) at $42^{\circ} \mathrm{C}$ for $30 \mathrm{~min}$ and $82^{\circ} \mathrm{C}$ for $10 \mathrm{sec}$. A CFX96 Real-Time System (Bio-Rad Laboratories, Inc., Hercules, CA, USA) was used to run the qPCR reactions with SYBR Premix Ex Taq II (Takara Biotechnology Co., Ltd.). The primers were: miR-128, forward 5'-GGCTCACAGTGAACCGG-3' and reverse 5'-GTGCAG GGTCCGAGGT-3'; and U6, forward 5'-CTCGCTTCGGCA GCACA-3' and reverse 5'-AACGCTTCACGAATTTGCGT-3'. The thermocycling conditions were as follows: $94^{\circ} \mathrm{C}$ for $45 \mathrm{sec}$, followed by 40 cycles of $95^{\circ} \mathrm{C}$ for $30 \mathrm{sec}$ and $60^{\circ} \mathrm{C}$ for $30 \mathrm{sec}$, and a final step at $72^{\circ} \mathrm{C}$ for 30 sec. miR-128 expression was quantified using the $2^{-\Delta \Delta \mathrm{Cq}}$ method (15).

Dual luciferase assay. 293 cells were purchased from Shanghai Cell Bank of Chinese Academy of Sciences and cultured in Dulbecco's modified Eagle's medium (Gibco; Thermo Fisher Scientific, Inc.) containing 10\% fetal bovine serum (Gibco; Thermo Fisher Scientific, Inc.), in $5 \% \mathrm{CO}_{2}$ and $95 \%$ air. The pGL3-PLK2 (Invitrogen; Thermo Fisher Scientific, Inc.)-wild-type 3'-UTR and the mutant 3'-UTR of SIRT1 were obtained from Shanghai GeneChem Co., Ltd. (Shanghai, China). The wild-type SIRT1-3'-UTR-pGL3-PLK2 (Shanghai GeneChem Co., Ltd.), the mutant SIRT1-3'-UTR-pGL3-PLK2 (Shanghai GeneChem Co., Ltd.) and miR-128 mimics were co-transfected into 293 cells $\left(1 \times 10^{6}\right.$ cells $\left./ \mathrm{ml}\right)$ using Lipofectamine ${ }^{\circledR} 2000$ reagent (Thermo Fisher Scientific, Inc.). After transfection for $24 \mathrm{~h}$, luciferase intensity was measured using a dual-luciferase assay kit (Promega Corporation, Madison, WI, USA) by a GloMax 20/20 luminometer (Promega Corporation). The absolute values of firefly luminescence were normalized to those of Renilla luciferase activity.

Hematoxylin and eosin $(H \& E)$ staining. The brain tissues were harvested, fixed in 4\% paraformaldehyde for 1-2 days at room temperature, processed and embedded into paraffin blocks. The brain tissue sections $(10 \mu \mathrm{m})$ were dipped into gradient ethanol (75-100\%) and stained with H\&E for $10 \mathrm{~min}$ at room temperature. The stained sections were observed with 
A

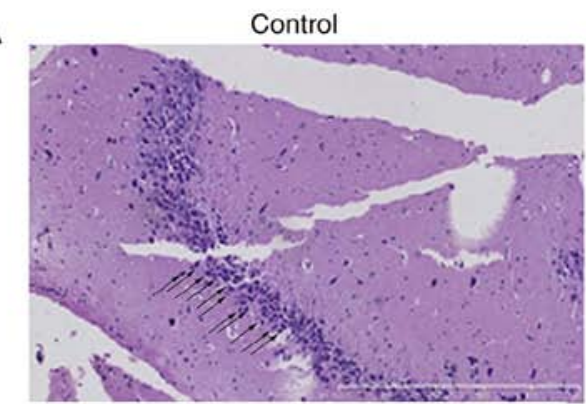

B
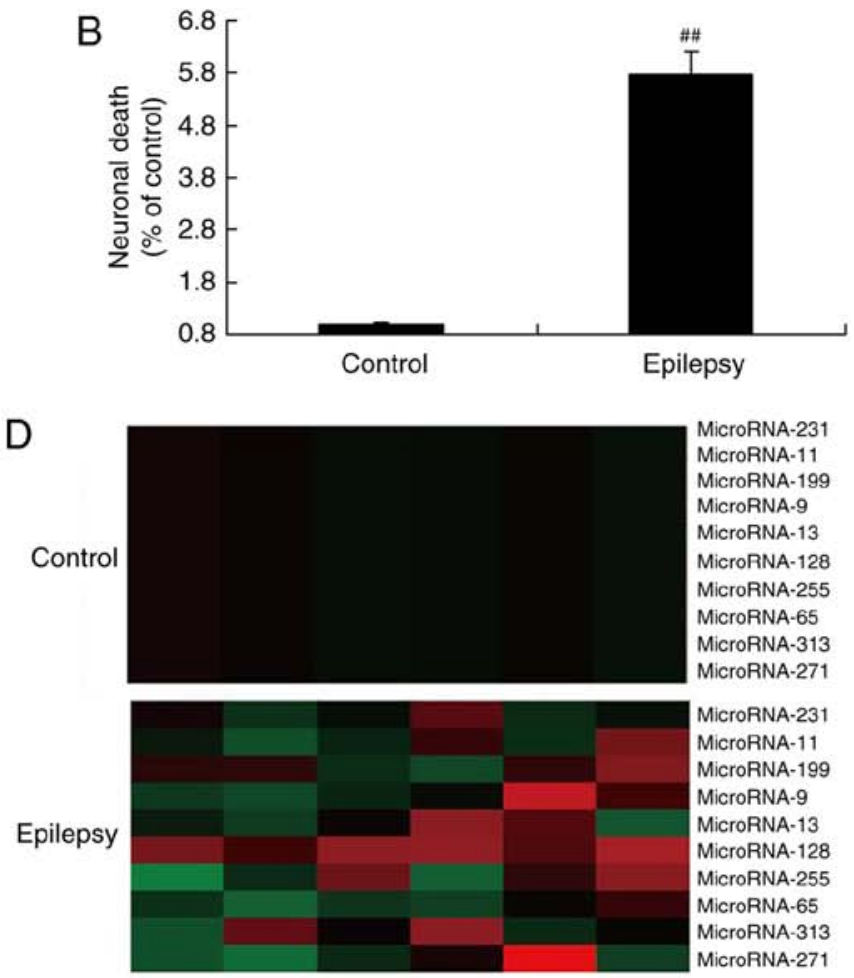

MicroRNA-231 MicroRNA-11 MicroRNA-199 MicroRNA-9 MicroRNA-13 MicroRNA-128 MicroRNA-255 MicroRNA-65 MicroRNA-313 MicroRNA-271

MicroRNA-231 MicroRNA-11 MicroRNA-199 MicroRNA-9 MicroRNA-13 MicroRNA-128 MicroRNA-255 MicroRNA-255 MicroRNA-65 MicroRNA-313
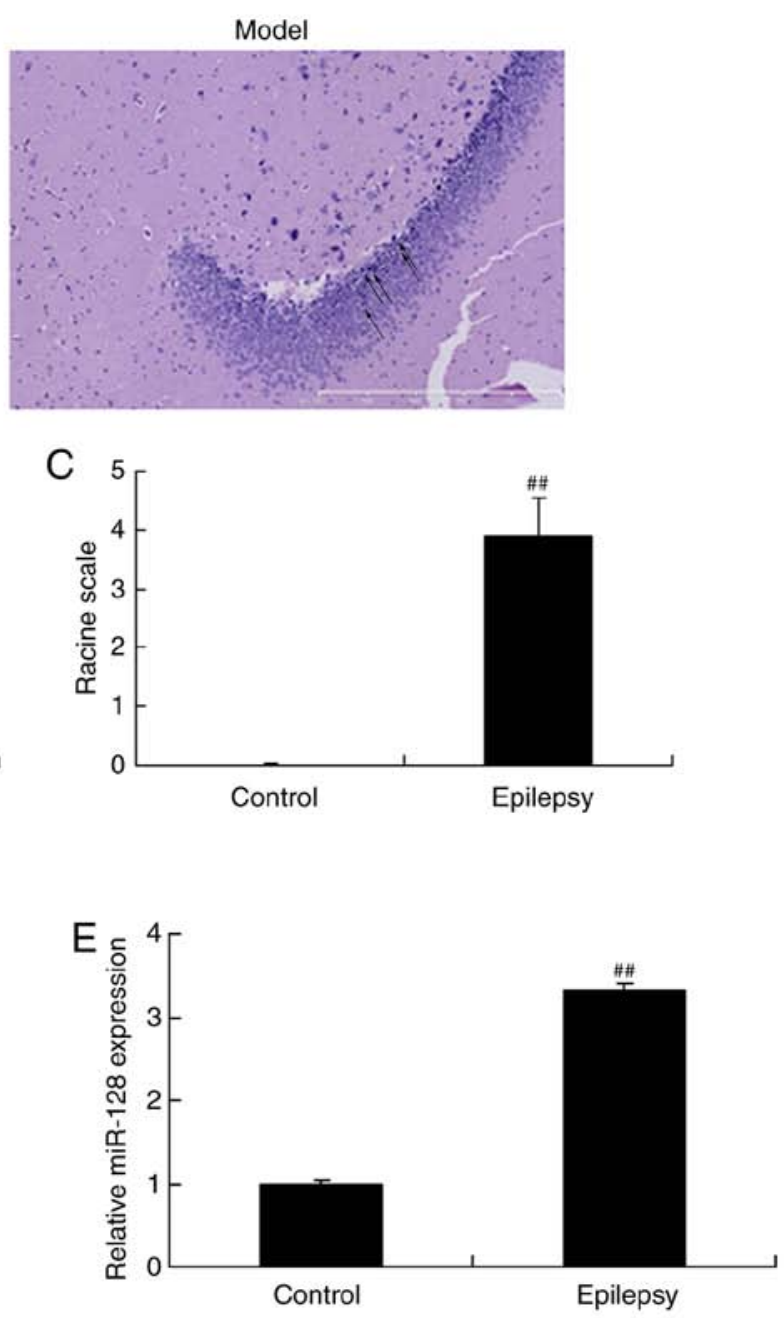

Figure 1. MicroRNA-128 expression in rats with epilepsy. (A) Hematoxylin and eosin staining of hippocampus samples from control and epilepsy rats (magnification, x100). Black arrows indicate nerve corpuscles. (B) Neuronal death and (C) racine scale. (D) MicroRNA expression levels in the brains of control and epilepsy model rats, as determined by (E) reverse transcription-quantitative polymerase chain reaction (control, $\mathrm{n}=6$; epilepsy group, $\mathrm{n}=8)$. ${ }^{\# \#} \mathrm{P}<0.01 \mathrm{compared}$ with control group.

an upright light microscope (magnification, x50; E600FN; Nikon Corporation, Tokyo, Japan).

Western blot analysis. Total proteins were extracted from brain tissues using a whole protein extraction kit (Nanjing KeyGen Biotech Co., Ltd., Nanjing, China). Total protein was quantified using a BCA assay kit (Beyotime Institute of Biotechnology). Total protein $(50 \mu \mathrm{g})$ was separated on 10-12\% SDS-PAGE and electrophoretically transferred to polyvinylidene fluoride membranes. Membranes were blocked in $5 \%$ bovine serum albumin (BSA; Beyotime Institute of Biotechnology) in TBS containing $0.1 \%$ Tween-20 (TBST) at room temperature for $2 \mathrm{~h}$. The membranes were subsequently incubated in TBST at $4^{\circ} \mathrm{C}$ overnight with the following primary antibodies (all from Santa Cruz Biotechnology, Inc., Dallas, TX, USA): SIRT1 (cat. no. sc-135791; 1:1,000), tumor protein p53 (cat. no. sc-47698; 1:1,000), BCL2 associated X (Bax; cat. no. sc-6236; 1:1,000), Cytochrome $c$ (cat. no. sc-13561; 1:1,000) and GAPDH (cat. no. sc-32233; 1:2,000). Following three washes with TBST, the membranes were incubated with horseradish peroxidase-conjugated secondary antibody (cat. no. sc-2004; 1:5,000; Santa Cruz Biotechnology, Inc.) at room temperature for $2 \mathrm{~h}$. Finally, protein signals were visualized using an Enhanced Chemiluminescence kit (Pierce; Thermo Fisher Scientific, Inc.) and analyzed using Image_Lab_3.0 (Bio-Rad Laboratories, Inc.).

Immunofluorescence analysis. Cells were washed with PBS and fixed with $4 \%$ paraformaldehyde for $15 \mathrm{~min}$ at room temperature. They were subsequently blocked with 5\% BSA and $0.1 \%$ Tris-X100 for $1 \mathrm{~h}$ at room temperature. Cells were incubated at $4{ }^{\circ} \mathrm{C}$ overnight with a primary antibody targeting SIRT1 (cat. no. sc-135791; 1:100; Santa Cruz Biotechnology, Inc.), followed by a secondary goat anti-rabbit immunoglobulin G-CFL 555 antibody (cat. no. sc-362272; 1:100; Santa Cruz Biotechnology, Inc.) for $1 \mathrm{~h}$ at room temperature. The nuclei were counterstained with DAPI for $30 \mathrm{~min}$ in the dark at room temperature. Finally, the samples were washed with PBS and observed by fluorescence microscopy (magnification, x200). 

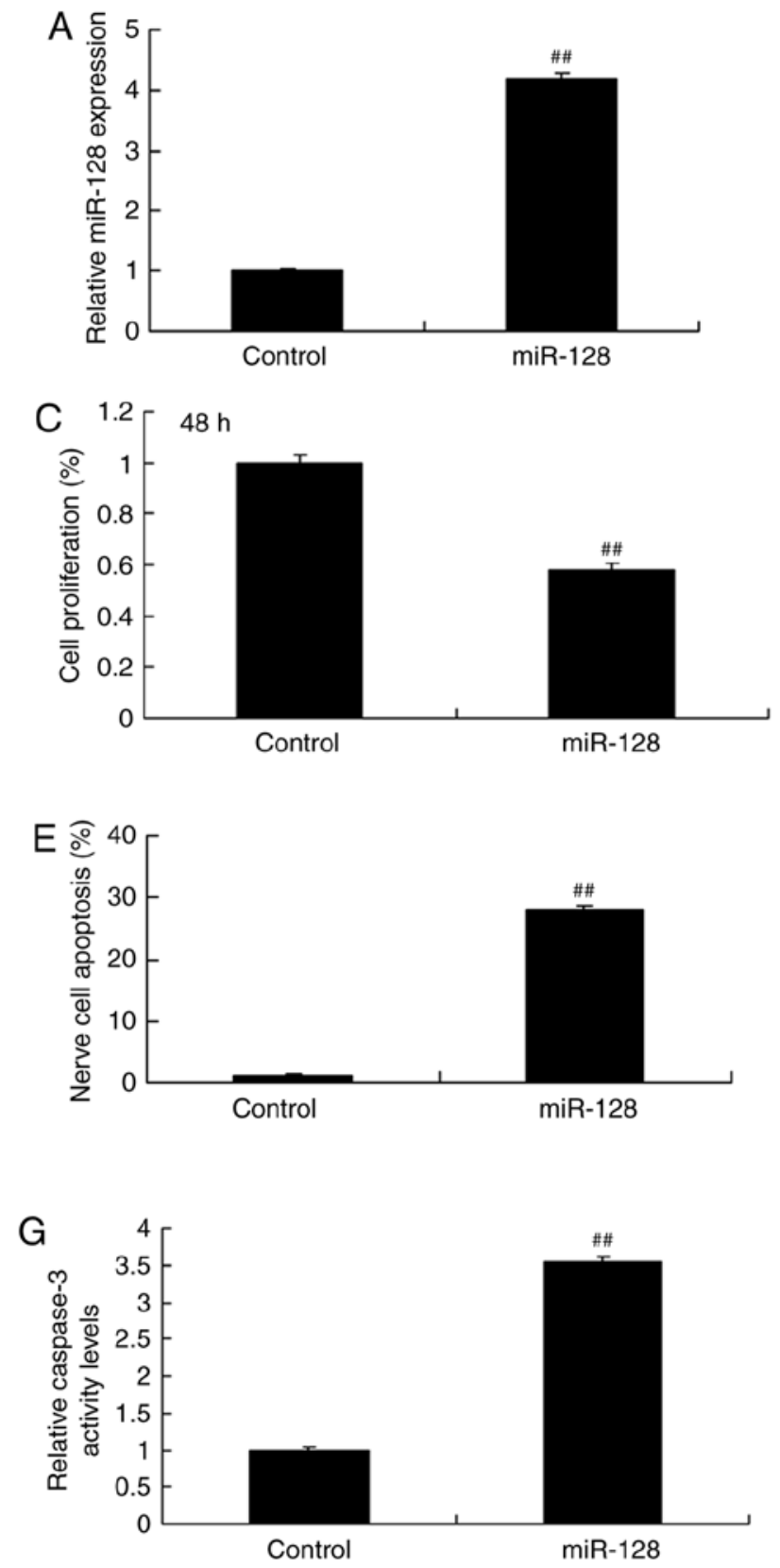
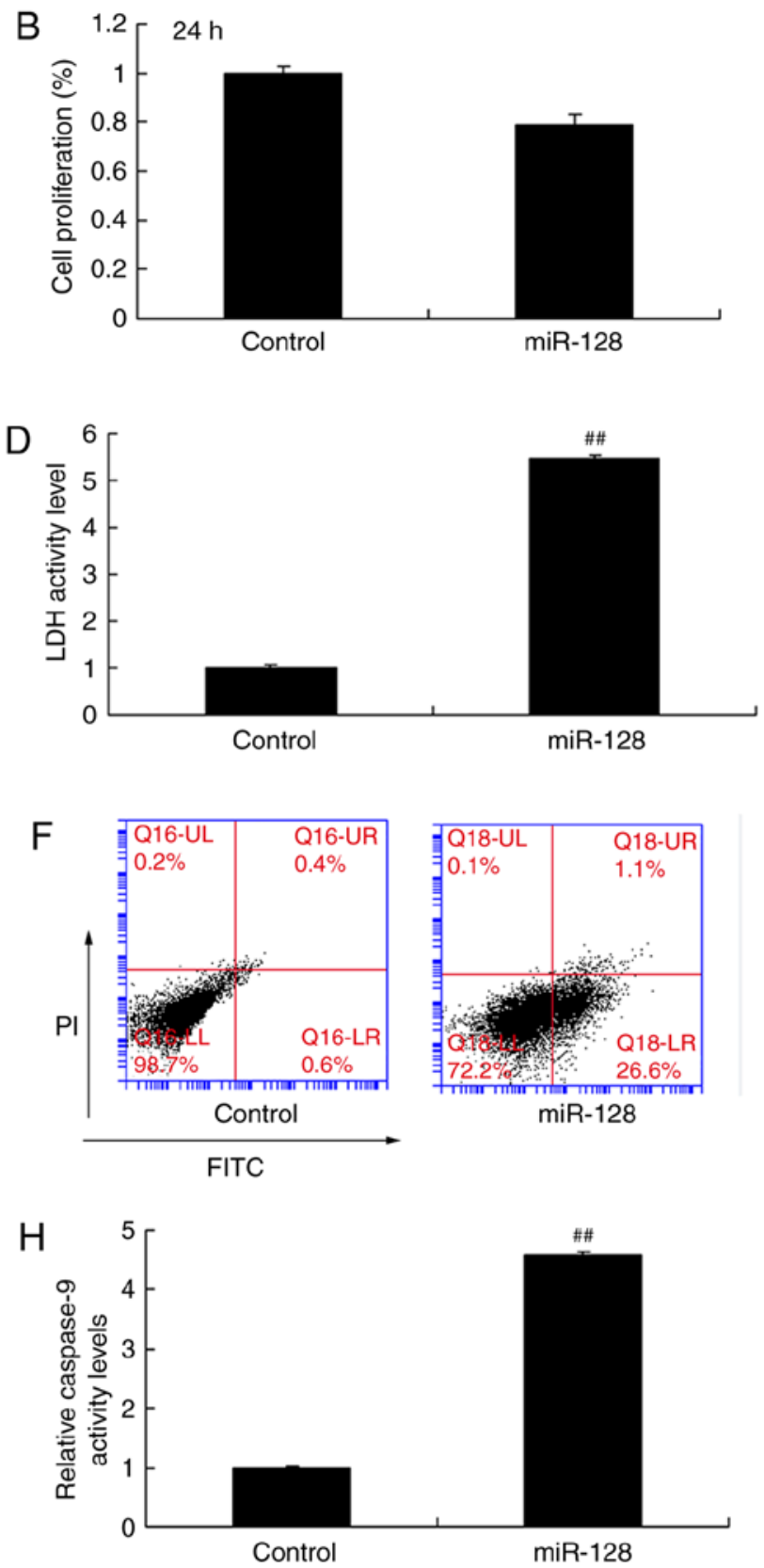

Figure 2. Effect of miR-128 overexpression on apoptosis. PC12 cells were transfected with either control or miR-128 mimics. (A) miR-128 levels were determined by reverse transcription-quantitative polymerase chain reaction. Cell proliferation assay at (B) 24 and (C) $48 \mathrm{~h}$ post-transfection. (D) LDH activity levels. (E) Quantification and (F) representative plots of flow cytometry analysis of apoptosis rates. (G) Caspase-3 and (H) caspase-9 activity levels. ${ }^{\#} \mathrm{P}<0.01$ compared with control group. LDH, lactate dehydrogenase; FITC, fluorescein isothiocyanate; PI, propidium iodide; miR, microRNA.

Statistical analysis. All data are expressed as mean \pm standard deviation ( $\mathrm{n}=3$ ) using SPSS 20.0 (IBM, Corp., Armonk, NY, USA). The statistical significance of the differences was evaluated by unpaired t-test (two-tailed) or one-way analysis of variance with Tukey's multiple comparison tests. $\mathrm{P}<0.05$ was considered to indicate a statistically significant difference.

\section{Results}

Expression of miR-128 in rats with epilepsy. Firstly, the difference in miR-128 expression between the brain tissues of the epilepsy model rats and normal control rats was examined. The results indicated that the number of nerve corpuscles in epilepsy rat model was decreased compared with the control group (normal rats; Fig. 1A), similar to results from a previous study (16). Neuronal death and racine scale were increased in the epilepsy rat model, compared with the control group (normal rats; Fig. 1B and C), which demonstrated that epilepsy was successfully established in the rats. qPCR was performed in the present study to detect the miR-128 expression levels. In addition, miR-128 expression levels in the brains of the epilepsy rats were significantly higher compared with the normal control rats (Fig. 1D).

Effect of miR-128 on apoptosis in epilepsy. The effect of miR-128 overexpression was further examined in vitro. Transfection of miR-128 mimics was used to upregulate the expression of miR-128 in PC12 cells (Fig. 2A). The results from 
A

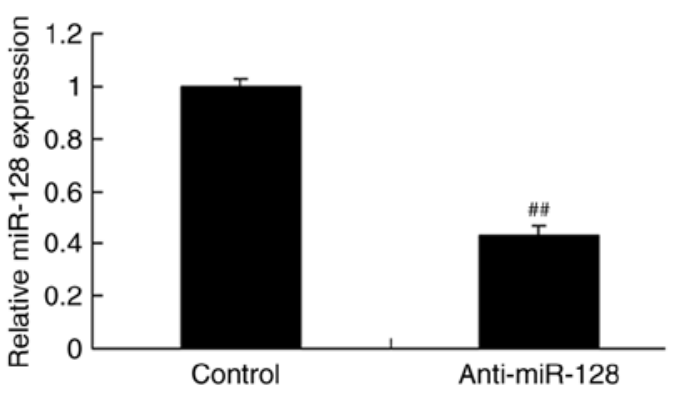

B

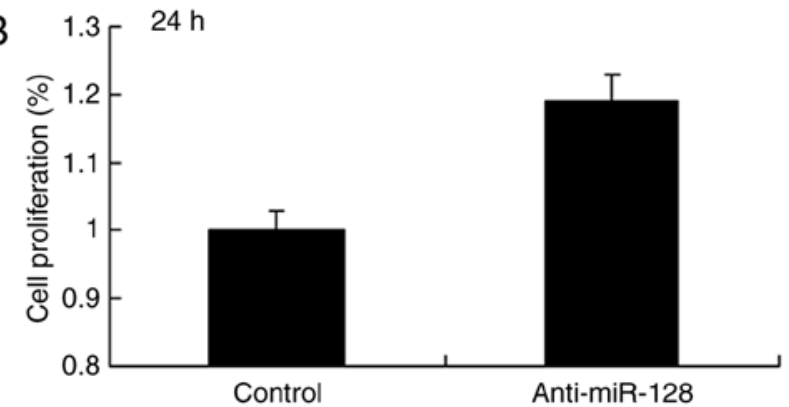

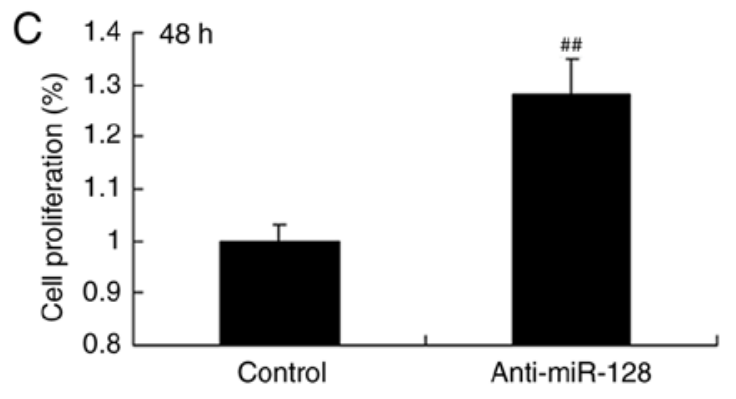
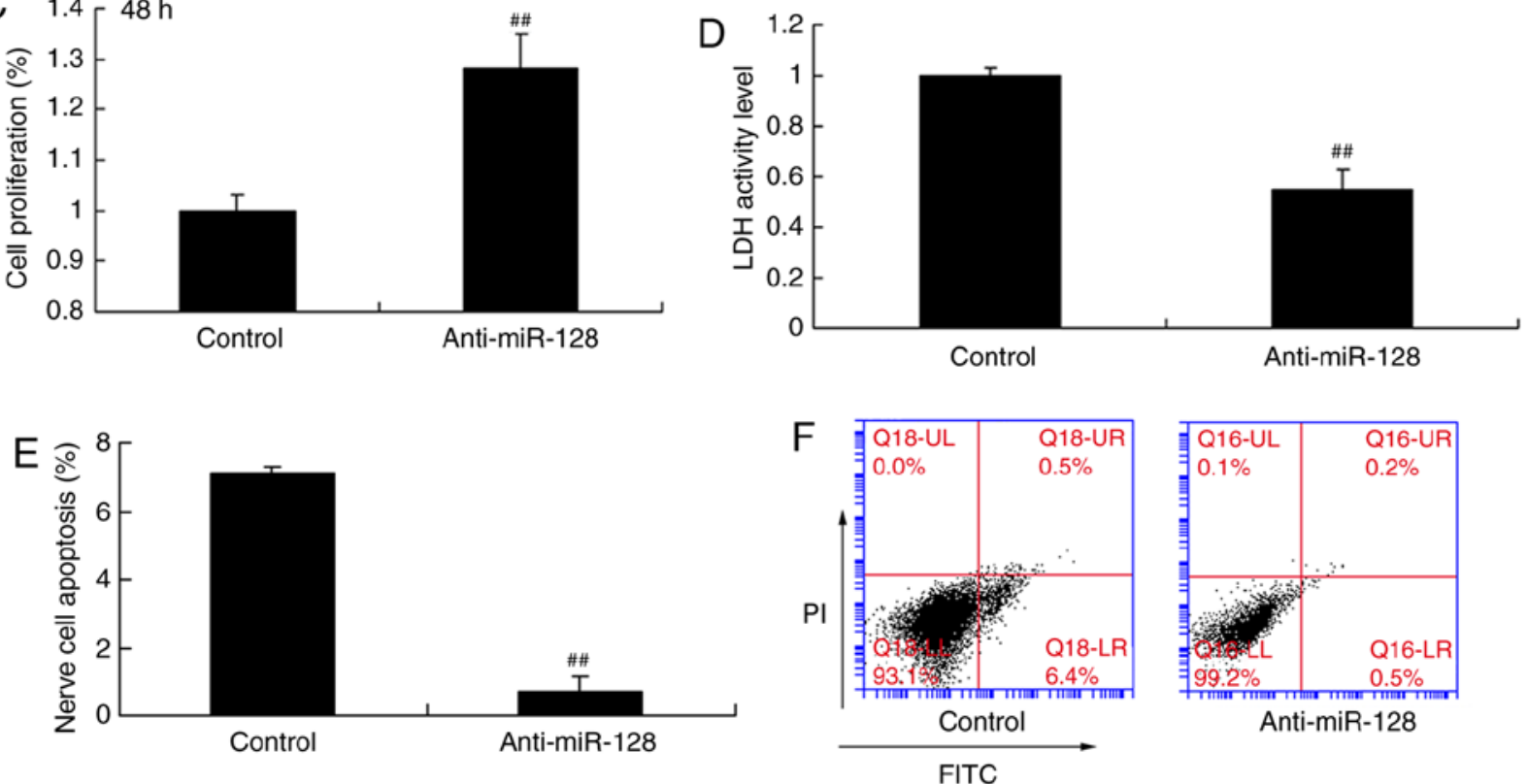

Anti-miR-128
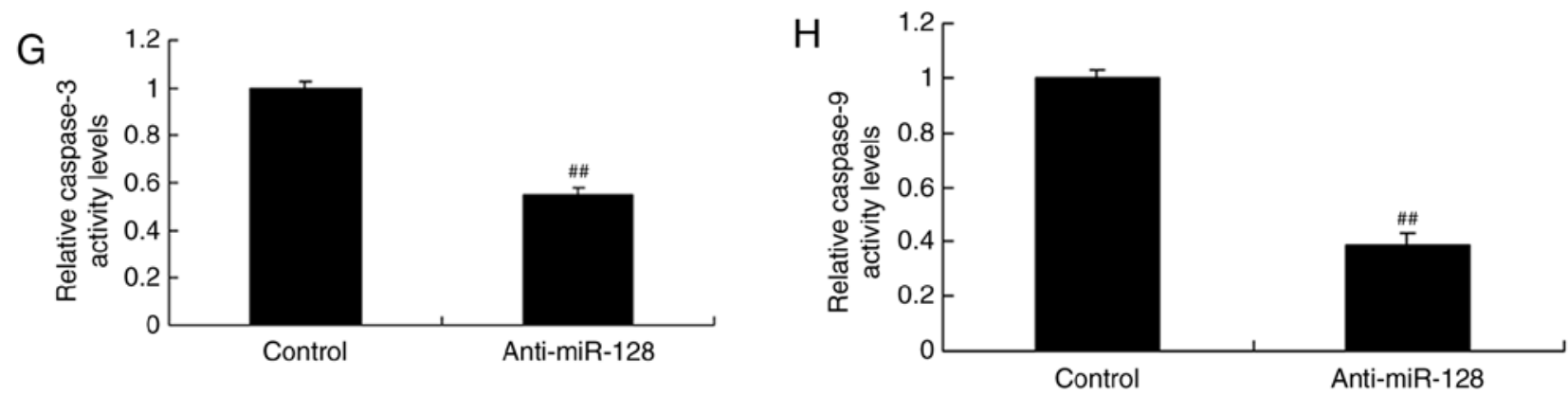

Figure 3. Effect of miR-128 downregulation on apoptosis. PC12 cells were transfected with either control or anti-miR-128 mimics. (A) miR-128 expression levels were determined by reverse transcription-quantitative polymerase chain reaction. Cell proliferation assay at (B) 24 and (C) $48 \mathrm{~h}$ post-transfection. (D) LDH activity levels. (E) Quantification and (F) representative plots of flow cytometry analysis of apoptosis rates. (G) Caspase-3 and (H) caspase-9 activity levels. ${ }^{\#} \mathrm{P}<0.01$ compared with control group. LDH, lactate dehydrogenase; FITC, fluorescein isothiocyanate; PI, propidium iodide; miR, microRNA.

an MTT assay demonstrated that overexpression of miR-128 significantly inhibited cell proliferation at $48 \mathrm{~h}$. Additionally, miR-128 overexpression increased LDH activity (Fig. 2D), promoted nerve cell apoptosis (Fig. 2E and F), and enhanced caspase-3/9 activity (Fig. 2G and $\mathrm{H}$ ) compared with the control group. Thus, the present results suggested that the function of miR-128 might be associated with nerve cell apoptosis.

Effect of anti-miR-128 on apoptosis in epilepsy. The effects of anti-miR-128 on regulating nerve cell apoptosis were additionally examined. As illustrated in Fig. 3A, transfection of PC12 cells with anti-miR-128 mimics significantly downregulated
miR-128 expression compared with the control group. miR-128 expression inhibition promoted cell proliferation at $48 \mathrm{~h}$ (Fig. 3B and C), while it decreased LDH activity (Fig. 3D), nerve cell apoptosis (Fig. 3E and F) and caspase-3/9 activity (Fig. 3G and $\mathrm{H}$ ) compared with the control group.

Effect of miR-128 on regulating the SIRT1 signaling pathway. Subsequently, the mechanism of miR-128 in regulating nerve cell apoptosis in epilepsy was evaluated. As illustrated in Fig. 4A and B, the miR-128 binding site was deleted from the wild-type UTR SIRT1 3'UTR and the luciferase activity of miR-128 was reduced in miR-128+wild-type UTR, compared 


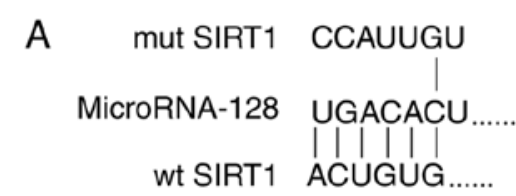

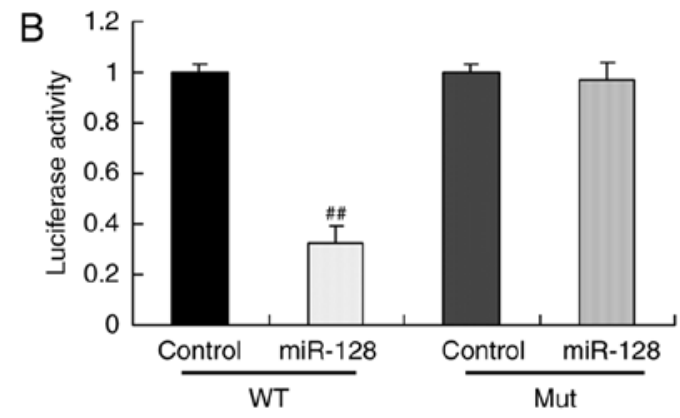
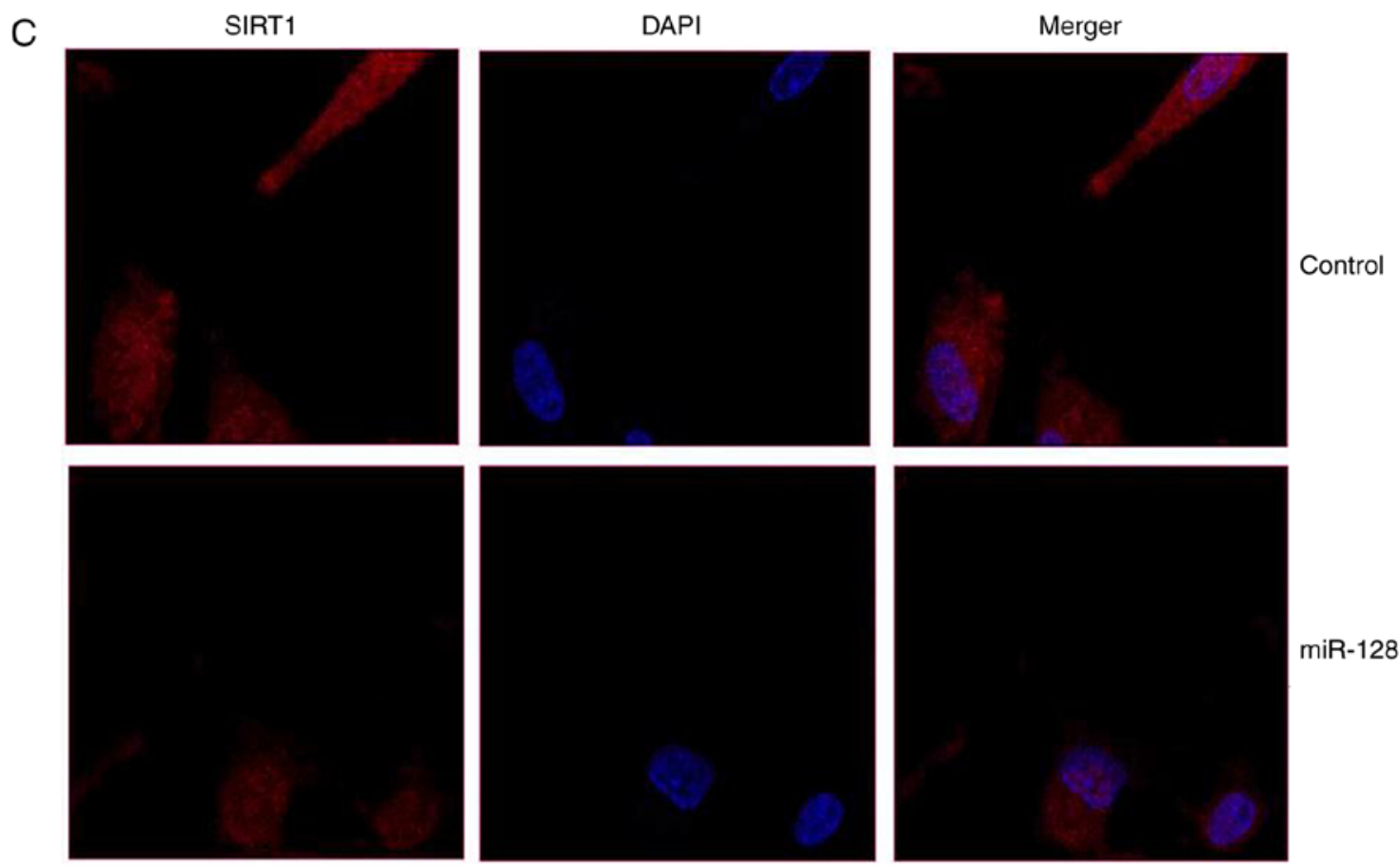

Figure 4. Effect of miR-128 on SIRT1 expression. (A) Schematic showing the binding site of miR-128 on the 3' untranslated region of SIRT1. (B) Luciferase assay results. (C) Immunofluorescence staining of SIRT1 protein expression. ${ }^{\# \#} \mathrm{P}<0.01$ compared with control group. SIRT1, sirtuin 1; mut, mutant; wt, wild-type; miR, microRNA.

with the control mimics+wild-type UTR group; however, the luciferase activity remained unaltered in the control mimics+mutUTR or miR-128+mutUTR, which suggested that the miR-127 was binding to the wild-type UTR of SIRT1. In addition, immunofluorescence analysis revealed that miR-128 mimics transfection suppressed SIRT1 protein expression in vitro compared with the cells transfected with control mimics (Fig. 4C). The results of Fig. 5A-E demonstrated that upregulation of miR-128 decreased SIRT1 protein expression, while it upregulated the protein expression of $\mathrm{p} 53$, Bax and Cytochrome $c$ in vitro compared with the control group. By contrast, downregulation of miR-128 by anti-miR-128 mimics transfection induced SIRT1 protein expression, and suppressed the protein expression of p53, Bax and Cytochrome $c$ compared with the control group (Fig. 5F-J). In conclusion, the present results suggested that the SIRT1 signaling pathway might be an important mediator of the anti-epileptic effect of miR-128 on apoptosis of PC12 cells in vitro.

SIRT1 promotion reverses the effects of miR-128. It was hypothesized in the present study that the SIRT1 signaling pathway was involved in the effect of miR-128. Consequently, the SIRT1 signaling pathway was examined by western blotting following incubation of the cells with CAY10602, a SIRT1 agonist. Western blotting results demonstrated that the SIRT1 agonist could induce the protein expression of SIRT1, while it suppressed p53, Bax and Cytochrome $c$ expression in PC12 cells compared with the miR-128 alone group (Fig. 6). In addition, incubation with the SIRT1 agonist inhibited the effect of miR-128 on cell proliferation (Fig. 7A), while it increased LDH activity (Fig. 7B), nerve cell apoptosis (Fig. 7C and D) and caspase-3/9 activity (Fig. 7E and F) in vitro compared with the miR-128 alone group.

Inhibition of $p 53$ reduces the effects of miR-128. To determine whether the p53 signaling pathway was functionally related to the homeostatic changes in the effect of miR-128, cells were treated with p53 inhibitor and apoptosis was measured. The results indicated that the p53 inhibitor significantly inhibited p53, Bax and Cytochrome $c$ compared with the miR-128 alone group (Fig. 8). Compared with the miR-128 group, p53 inhibition additionally suppressed the effects of miR-128 on inhibiting cell proliferation and promoting LDH activity, nerve cell apoptosis and caspase-3/9 activity (Fig. 9). 

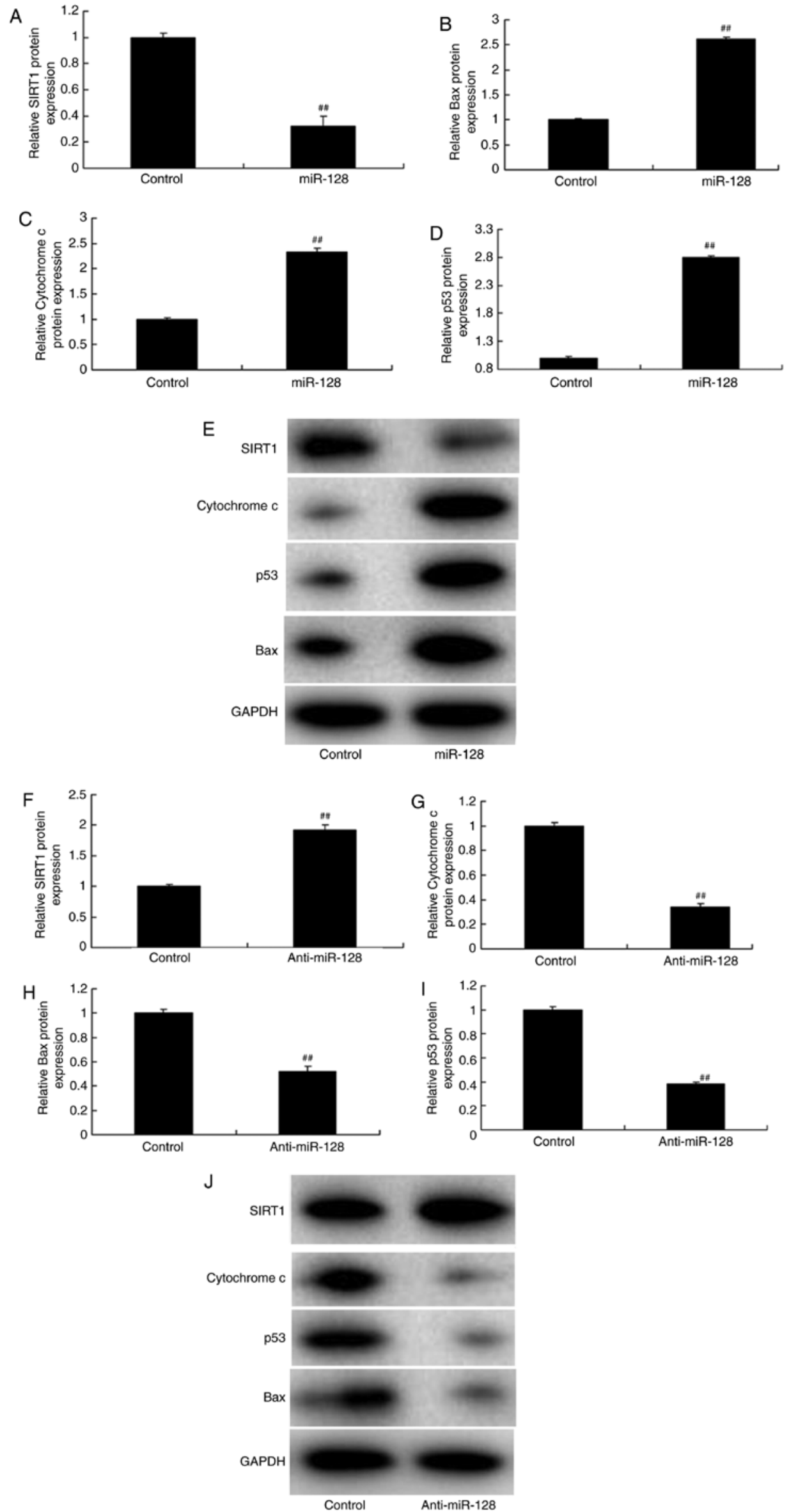

Figure 5. Effect of miR-128 on SIRT1/Bax/Cytochrome $c / p 53$ signaling. (A-D) Quantification and (E) representative blots from western blot analysis of PC12 cells transfected with either control or miR-128 mimics. (F-I) Quantification and (J) representative blots from western blot analysis of PC12 cells transfected with either control or anti-miR-128 mimics. ${ }^{\# \#} \mathrm{P}<0.01$ compared with control group. SIRT1, sirtuin 1; p53, tumor protein p53; Bax, BCL2 associated X; miR, microRNA. 

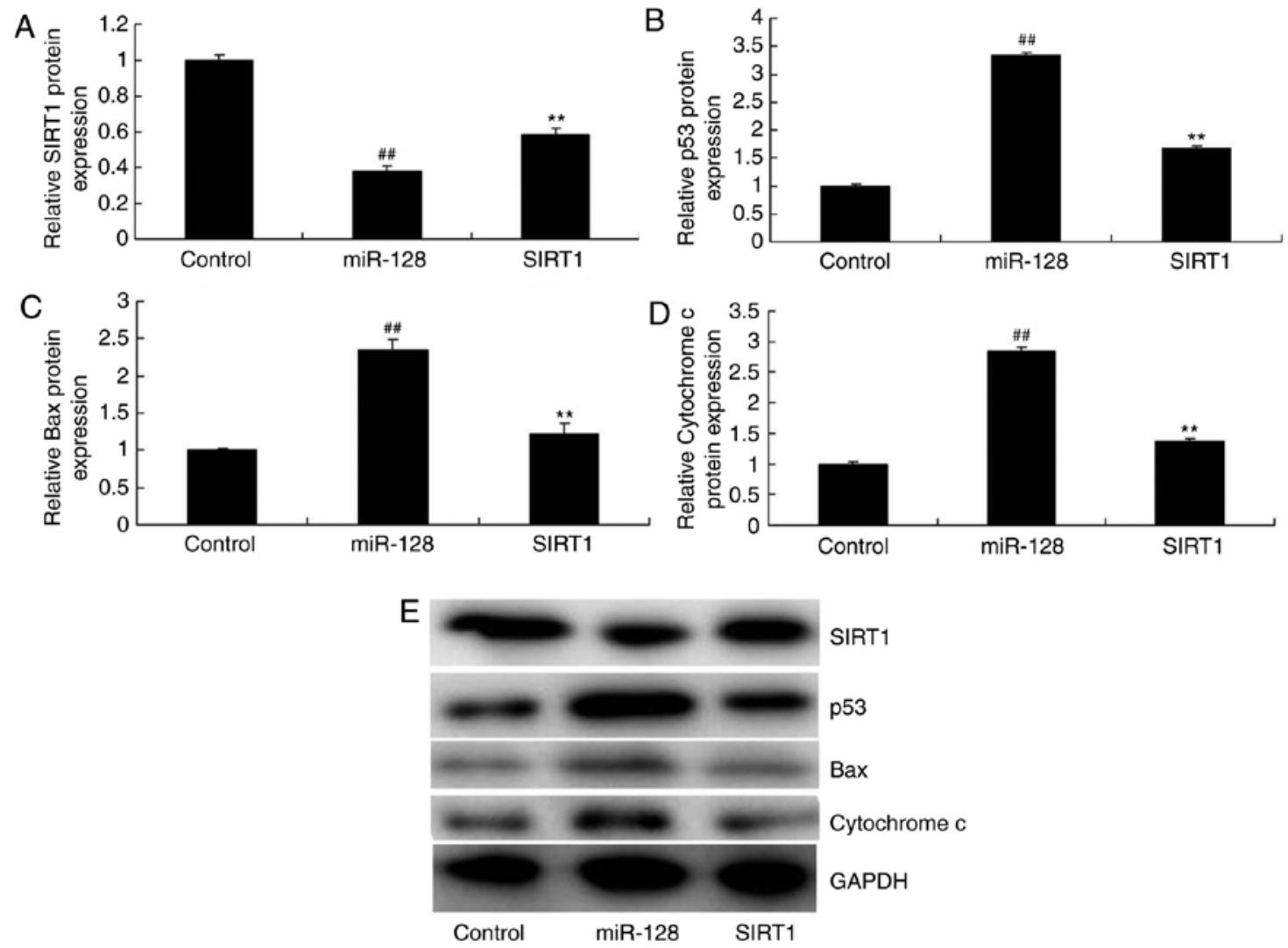

Figure 6. SIRT1 promotion reverses the effect of miR-128. (A-D) Quantification and (E) representative blots from western blot analysis of PC12 cells treated with control, or miR-128 mimics alone, or miR-128 mimics and a SIRT1 agonist. ${ }^{\# \#} \mathrm{P}<0.01$ compared with control group; ${ }^{* *} \mathrm{P}<0.01$ compared with miR-128 group. SIRT1, sirtuin 1; p53, tumor protein p53; Bax, BCL2 associated X; miR, microRNA.
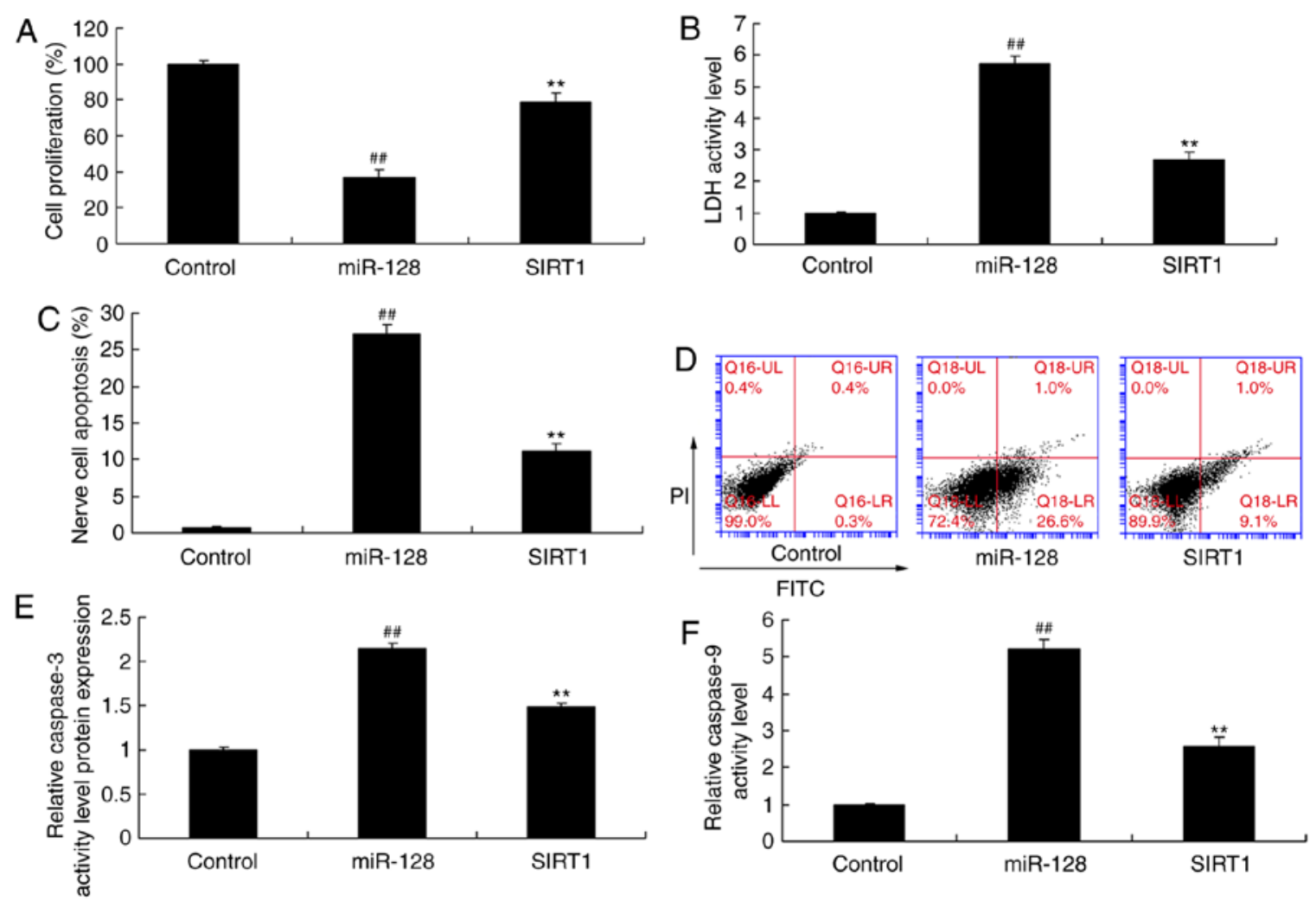

Figure 7. SIRT1 promotion reverses the function of anti-miR-128 on apoptosis. (A) Cell proliferation, (B) LDH activity levels, (C and D) apoptosis rate, and (E and F) caspase-3 and caspase-9 activity levels were measured in cells treated with control, or miR-128 mimics alone, or miR-128 mimics and a SIRT1 agonist. ${ }^{\# \#} \mathrm{P}<0.01$ compared with control group; ${ }^{* *} \mathrm{P}<0.01$ compared with miR-128 group. SIRT1, sirtuin 1; LDH, lactate dehydrogenase; FITC, fluorescein isothiocyanate; PI, propidium iodide; miR, microRNA. 

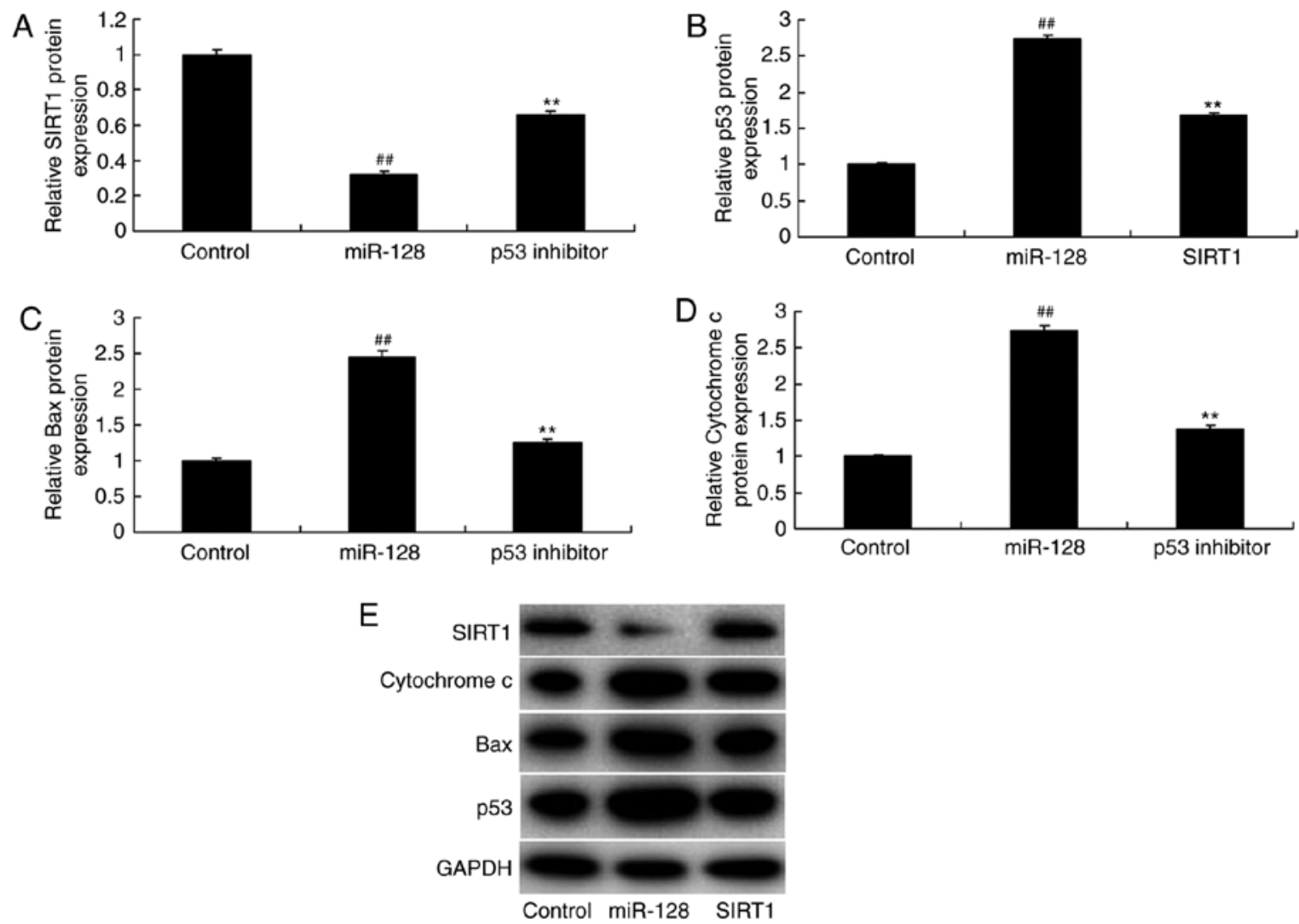

Figure 8. Inhibition of p53 reverses the effect of miR-128. (A-D) Quantification and (E) representative blots from western blot analysis of PC12 cells treated with control, or miR-128 mimics alone, or miR-128 mimics and a p53 inhibitor. ${ }^{\# \#} \mathrm{P}<0.01$ compared with control group; ${ }^{* *} \mathrm{P}<0.01$ compared with miR-128 group. SIRT1, sirtuin 1; p53, tumor protein p53; Bax, BCL2 associated X; miR, microRNA.

\section{Discussion}

Epilepsy is a common nervous system disease, the morbidity of which is $\sim 25 / 1,000$ in the general population (6). It severely affects the life, work and learning of patients, which has thus become a chronic central nervous system disease (5). Therefore, investigating the pathogenesis of epilepsy is an important topic in neuroscience currently (5). In the present study, miR-128 expression was demonstrated to be upregulated in an epilepsy rat model compared with normal rats, while the upregulation of miR-128 induced nerve cell apoptosis in vitro. Only one cell line, the PC1 2 cell line, was used in the present study, therefore further studies are required in the future to verify the results in additional cell lines and models.

miRNA are able to regulate protein synthesis at the translation level. A previous study demonstrated that a number of miRNAs in the brain are closely associated with synaptic reorganization (8). Dendritic spine exists in small protuberance with prominent dendrite. It has become the extruding components of the primary excitatory synapse, the dynamic alteration of which is an important form of synaptic reorganization (10). Anti-miR-128 is a miRNA with brain specificity, which may function in the dendrite of nerve cells and negatively regulate the size of dendritic spine (17). The present study presented evidence that anti-miR-128 expression in an epilepsy rat model was higher compared with normal rats. A previous study has reported that miR-183, miR-135a, miR-125b, miR-30c and miR-128 are upregulated at the seizure-associated phases and in patients with temporal lobe epilepsy (13). The present results demonstrated that downregulation of miR-128 promoted cell proliferation at $48 \mathrm{~h}$, while it reduced LDH activity, nerve cell apoptosis and caspase-3/9 activity in nerve cells in vitro.

SIRT1 is mainly expressed in neurons in the nervous system, such as cortex, hippocampus, cerebellum and hypothalamus (11). It serves a vital role in neuron apoptosis and differentiation, cognitive function and synaptic plasticity (11). SIRT1 exhibits protective effects on multiple acute and chronic nervous system diseases (18). These diseases include cerebral ischemia, Wallerian degeneration, Huntington's disease, axonal injury, Alzheimer's disease, Parkinson's disease, multiple sclerosis and amyotrophic lateral sclerosis (18). Accumulating evidence has indicated that SIRT1 is closely associated with epilepsy (18). Specifically, Resveratrol, the SIRT1 agonist, has anti-epileptic effect on kainite- and $\mathrm{FeCl} 3$-induced epileptic animal models (19). The present findings suggested that miR-128 directly binds and regulates SIRT1 expression. In addition, upregulation of miR-128 induced SIRT1 protein expression, while it suppressed the protein expression of $\mathrm{p} 53$, Bax and Cytochrome $c$ in vitro. Promotion of SIRT1 reduced the effect of miR-128 on nerve cells in vitro. A previous study indicated that miR-128 was able to promote apoptosis in human cancer via the p53/Bak axis through SIRT1 (20), whereas miR-128 has additionally been demonstrated to target SIRT1 in glioma subtypes (21).

The $\mathrm{p} 53$ gene is located on human chromosome 17p13.1. It is the most common pro-apoptotic gene that serves a key role in neural apoptosis (22). p53 is highly expressed in the case of neural apoptosis (22). By contrast, the application of a p53 gene 

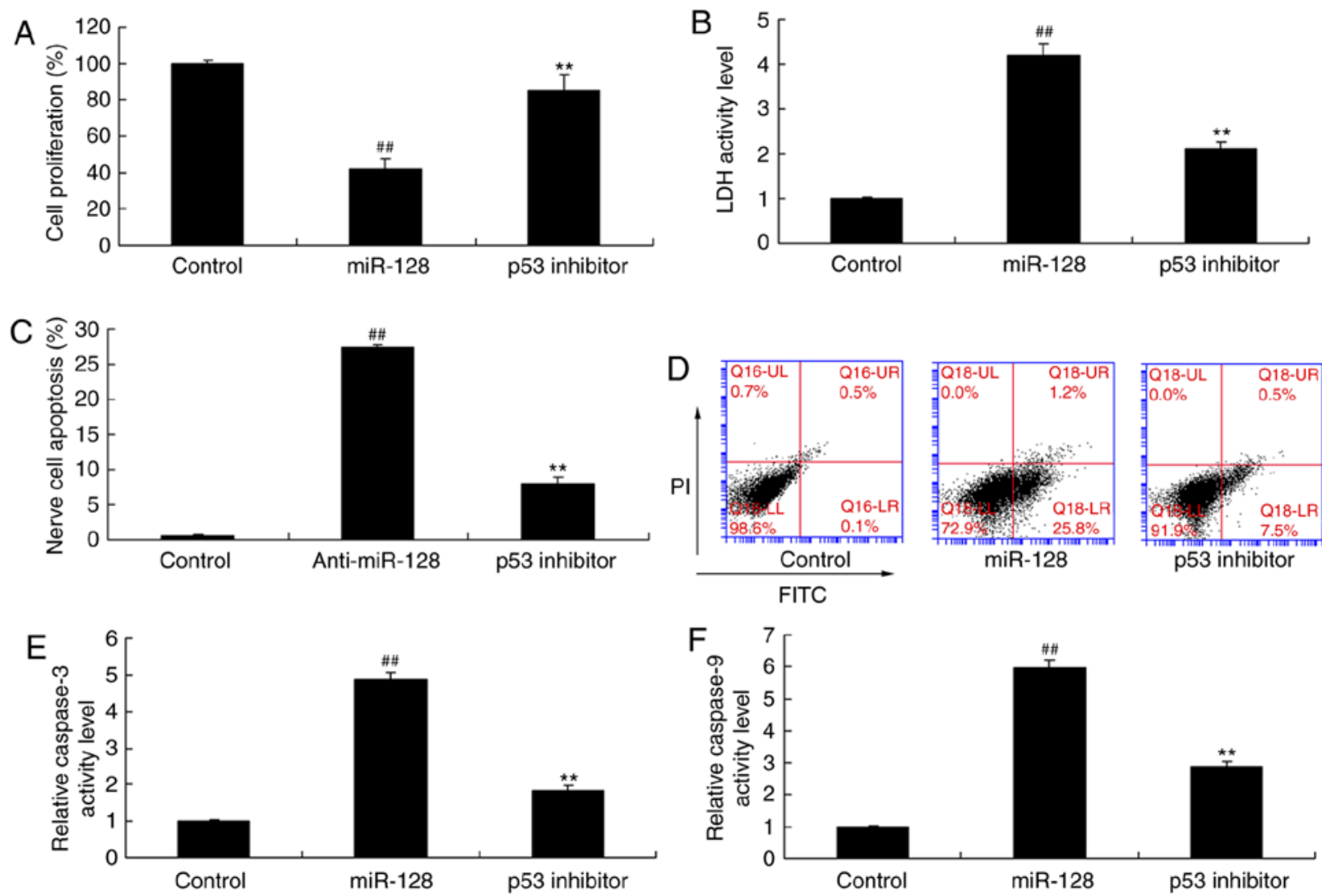

Figure 9. p53 inhibition reverses the function of anti-miR-128 on apoptosis. (A) Cell proliferation, (B) LDH activity levels, (C and D) apoptosis rate, and (E and F) caspase-3 and caspase-9 activity levels were measured in cells treated with control, or miR-128 mimics alone, or miR-128 mimics and a p53 inhibitor. ${ }^{\# \#} \mathrm{P}<0.01$ compared with control group; ${ }^{* *} \mathrm{P}<0.01$ compared with miR-128 group. SIRT1, sirtuin 1; LDH, lactate dehydrogenase; FITC, fluorescein isothiocyanate; PI, propidium iodide; miR, microRNA.

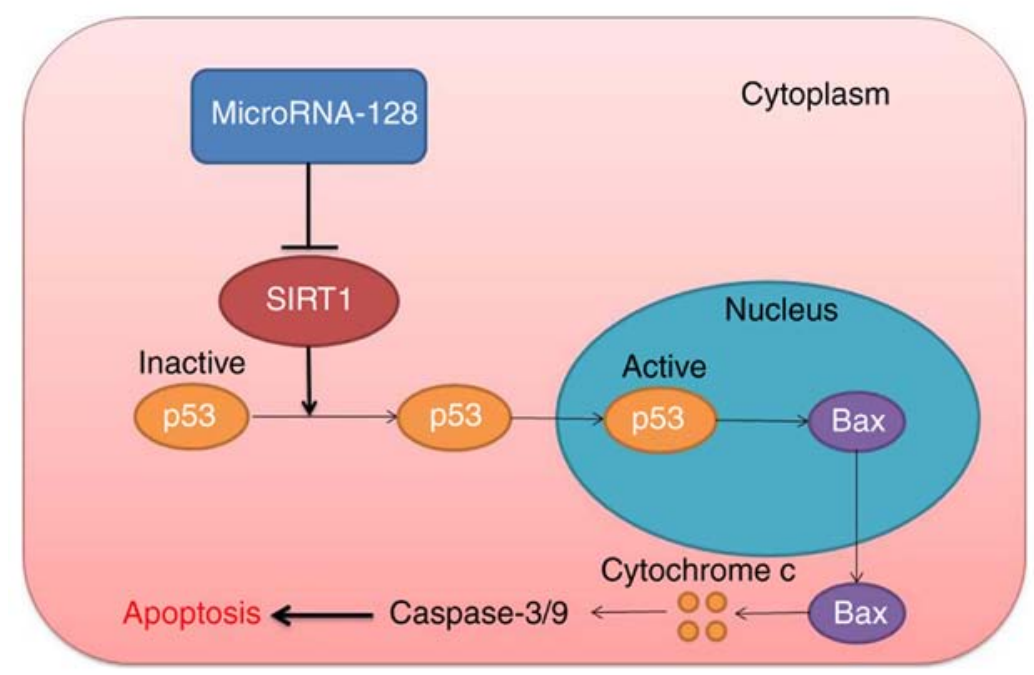

Figure 10. miR-128 exerts pro-apoptotic effects in PC12 nerve cells through the SIRT1 cascade in an in vitro model. SIRT1, sirtuin 1; p53, tumor protein p53; Bax, BCL2 associated X; miR, microRNA.

blocker can suppress apoptosis. p53 protein immunoreactivity was remarkably enhanced in hippocampus samples that were surgically removed from patients with refractory temporal lobe epilepsy (23). In addition, the Bax gene is one of the important regulatory genes during cell apoptosis (24). Bax is located on the mitochondrial outer membrane (25). It can exert its apoptotic effect through inhibiting tBid insertion, Bax transposition and
Bax/Bax oligomerization on the mitochondrial membrane (25). The present study demonstrated that p53 inhibition reduced the effect of miR-128 on epilepsy. A previous study has additionally suggested that miR-128 promotes apoptosis in human cancers via the p53/Bak axis through SIRT1 (20).

Finally, the present results demonstrated that miR-128 levels were increased in epilepsy in vivo, and downregulation 
of miR-128 induced nerve cell apoptosis through the SIRT1/p53/Bax/Cytochrome c/caspase signaling pathway (Fig. 10). Therefore, upregulation of miR-128 may promote apoptosis in epilepsy model in vivo and in vitro through the SIRT1/p53/Bax/Cytochrome $c /$ caspase signaling pathway. Therefore, miR-128 may have potential as an antiepileptic target in the clinic.

\section{Acknowledgements}

Not applicable.

\section{Funding}

No funding was received.

\section{Availability of data and materials}

The analyzed datasets generated during the study are available from the corresponding author on reasonable request.

\section{Authors' contributions}

WWW designed the experiment. DZC, YLC, XFY, MZ and YYY performed the experiments. WWW and DZC analyzed the data. WWW wrote the manuscript. All authors read and approved the final manuscript.

\section{Ethics approval and consent to participate}

Protocols involving animals in the present study were approved by the Institutional Animal Care and Ethics Committee of Liaocheng People's Hospital (Liaocheng, China).

\section{Patient consent for publication}

Not applicable.

\section{Competing interests}

The authors declare that they have no competing interests.

\section{References}

1. Freitas-Lima P, Alexandre V Jr, Pereira LR, Feletti F, Perucca E and Sakamoto AC: Influence of enzyme inducing antiepileptic drugs on the pharmacokinetics of levetiracetam in patients with epilepsy. Epilepsy Res 94: 117-120, 2011

2. Abd El Naby SA and Naguib YM: Sociodemographic, electrophysiological, and biochemical profiles in children with attention deficit hyperactivity disorder and/or epilepsy. Behav Neurol 2018: 8932817, 2018.

3. Angus-Leppan H: Diagnosing epilepsy in neurology clinics: A prospective study. Seizure 17: 431-436, 2008.

4. Phabphal K, Geater A, Limapichat K, Sathirapanya P, Setthawatcharawanich S and Leelawattana R: Effect of switching hepatic enzyme-inducer antiepileptic drug to levetiracetam on bone mineral density, 25 hydroxyvitamin $\mathrm{D}$, and parathyroid hormone in young adult patients with epilepsy. Epilepsia 54: e94-e98, 2013.

5. Ryvlin P, Gilliam FG, Nguyen DK, Colicchio G, Iudice A, Tinuper P, Zamponi N, Aguglia U, Wagner L, Minotti L, et al: The long-term effect of vagus nerve stimulation on quality of life in patients with pharmacoresistant focal epilepsy: The PuLsE (Open Prospective Randomized Long-term Effectiveness) trial. Epilepsia 55: 893-900, 2014.
6. Dalal K, Devarajan E, Pandey RM, Subbiah V and Tripathi M: Role of reflexology and antiepileptic drugs in managing intractable epilepsy-a randomized controlled trial. Forsch Komplementmed 20: 104-111, 2013.

7. Reschke CR and Henshall DC: microRNA and Epilepsy. Adv Exp Med Biol 888: 41-70, 2015.

8. Moon J, Lee ST, Choi J, Jung KH, Yang H, Khalid A, Kim JM, Park KI, Shin JW, Ban JJ, et al: Unique behavioral characteristics and microRNA signatures in a drug resistant epilepsy model. PLoS One 9: e85617, 2014.

9. Srivastava A, Dixit AB, Banerjee J, Tripathi $M$ and Sarat Chandra P: Role of inflammation and its miRNA based regulation in epilepsy: Implications for therapy. Clin Chim Acta 452: 1-9, 2015.

10. Li MM, Li XM, Zheng XP, Yu JT and Tan L: MicroRNAs dysregulation in epilepsy. Brain Res 1584: 94-104, 2014.

11. Hall AM, Brennan GP, Nguyen TM, Singh-Taylor A, Mun HS, Sargious MJ and Baram TZ: The Role of Sirt1 in Epileptogenesis. eNeuro 4: ENEURO.0301-16.2017, 2017.

12. Wang D, Li Z, Zhang Y, Wang G, Wei M, Hu Y, Ma S, Jiang Y, Che N, Wang X, et al: Targeting of microRNA-199a-5p protects against pilocarpine-induced status epilepticus and seizure damage via SIRT1-p53 cascade. Epilepsia 57: 706-716, 2016.

13. Alsharafi W and Xiao B: Dynamic expression of MicroRNAs $(183,135 \mathrm{a}, 125 \mathrm{~b}, 128,30 \mathrm{c}$ and $27 \mathrm{a})$ in the rat pilocarpine model and temporal lobe epilepsy patients. CNS Neurol Disord Drug Targets 14: 1096-1102, 2015.

14. Wang L, Liang L, Yang T, Qiao Y, Xia Y, Liu L, Li C, Lu P and Jiang $\mathrm{X}$ : A pilot clinical study of apatinib plus irinotecan in patients with recurrent high-grade glioma: Clinical trial/experimental study. Medicine (Baltimore) 96: e9053, 2017.

15. Livak KJ and Schmittgen TD: Analysis of relative gene expression data using real-time quantitative PCR and the 2(-Delta Delta C(T)) method. Methods 25: 402-408, 2001.

16. Chen $\mathrm{L}$, Zheng $\mathrm{H}$ and Zhang $\mathrm{S}$ : Involvement of upregulation of miR-210 in a rat epilepsy model. Neuropsychiatr Dis Treat 12: 1731-1737, 2016.

17. Wang XM, Jia RH, Wei D, Cui WY and Jiang W: MiR-134 blockade prevents status epilepticus like-activity and is neuroprotective in cultured hippocampal neurons. Neurosci Lett 572: 20-25, 2014.

18. Wang W, Zhang J, Li Y, Yang X, He Y, Li T, Ren F, Zhang J and Lin R: Divalproex sodium enhances the anti-leukemic effects of imatinib in chronic myeloid leukemia cells partly through SIRT1. Cancer Lett 356: 791-799, 2015.

19. Qian C, Jin J, Chen J, Li J, Yu X, Mo H and Chen G: SIRT1 activation by resveratrol reduces brain edema and neuronal apoptosis in an experimental rat subarachnoid hemorrhage model. Mol Med Rep 16: 9627-9635, 2017.

20. Adlakha YK and Saini N: miR-128 exerts pro-apoptotic effect in a p53 transcription-dependent and -independent manner via PUMA-Bak axis. Cell Death Dis 4: e542, 2013.

21. Lages E, Guttin A, El Atifi M, Ramus C, Ipas H, Dupré I, Rolland D, Salon C, Godfraind C, deFraipont F, et al: MicroRNA and target protein patterns reveal physiopathological features of glioma subtypes. PLoS One 6: e20600, 2011.

22. Engel T, Murphy BM, Schindler CK and Henshall DC: Elevated p53 and lower MDM2 expression in hippocampus from patients with intractable temporal lobe epilepsy. Epilepsy Res 77: 151-156, 2007.

23. Araki T, Shinoda S, Schindler CK, Quan-Lan J, Meller R, Taki W, Simon RP and Henshall DC: Expression, interaction, and proteolysis of death-associated protein kinase and p53 within vulnerable and resistant hippocampal subfields following seizures. Hippocampus 14: 326-336, 2004.

24. Zhao H, Lin G, Shi M, Gao J, Wang Y, Wang H, Sun H and Cao Y: The mechanism of neurogenic pulmonary edema in epilepsy. J Physiol Sci 64: 65-72, 2014.

25. Rabie T, Mühlhofer W, Bruckner T, Schwab A, Bauer AT, Zimmermann M, Bonke D, Marti HH and Schenkel J: Transient protective effect of B-vitamins in experimental epilepsy in the mouse brain. J Mol Neurosci 41: 74-79, 2010. 